\title{
p90RSK Inhibition Ameliorates TGF- $\beta 1$ Signaling and Pulmonary Fibrosis by Inhibiting Smad3 Transcriptional Activity
}

\author{
Suji Kim ${ }^{a, b}$ Jung-Hwa Han ${ }^{a, b}$ Sujin Kima,b Heejung Lee ${ }^{a, b} \quad$ Jae-Ryong Kim ${ }^{b}$ \\ Jae Hyang Limc Chang-Hoon Woo ${ }^{a, b}$ \\ aDepartment of Pharmacology, Yeungnam University College of Medicine, Daegu, Republic of Korea, \\ bSmart-Ageing Convergence Research Center, Yeungnam University College of Medicine, Daegu, \\ Republic of Korea, 'Department of Microbiology, Ewha Womans University College of Medicine, Seoul, \\ Republic of Korea
}

\section{Key Words \\ Pulmonary fibrosis $\cdot$ p90RSK $・$ TGF- $\beta 1 \cdot E C M \cdot E M T$}

\begin{abstract}
Background/Aims: Idiopathic pulmonary fibrosis (IPF) is a specific form of progressive and chronic interstitial lung disease of unknown cause. IPF is characterized by excessive deposition of extracellular matrix (ECM) and destructive pathological remodeling due to epithelial-tomesenchymal transition (EMT). Eventually, lung interstitium thickens and stiffens and breathing becomes difficult. It has been well established that the transforming growth factor- $\beta 1$ (TGF- $\beta 1$ )/Smad signaling pathway plays a critical role in the pathogenesis of pulmonary fibrosis. TGF- $\beta 1$-mediated activation of mitogen activated protein kinase (MAPK) family affects Smad signaling. p90RSK is a serine/threonine kinase and is activated by the extracellular signal-regulated kinase (ERK) signaling pathway. However, the roles played by p90RSK in TGF- $\beta 1$ signaling and the pathogenesis of pulmonary fibrosis remain unknown. Methods: We investigated whether p90RSK regulates the pathogenesis of pulmonary fibrosis using in vitro and in vivo systems and Western blotting, real-time quantitative PCR, transcriptional activity assays and immunofluorescence studies. Results: Pharmacological inhibition of p90RSK by FMK or inhibition of p90RSK with adenoviral vector encoding a dominant negative form of p90RSK suppressed TGF- $\beta 1$-induced ECM accumulation and EMT in lung epithelial cells and fibroblasts. Interestingly, FMK significantly inhibited TGF- $\beta 1$-induced smad binding elementdependent transcriptional activity, but not Smad3 phosphorylation and nuclear translocation. Furthermore, in a mouse model of bleomycin-induced lung fibrosis, FMK ameliorated pulmonary fibrosis. Conclusion: These findings indicate that p90RSK plays critical roles in pulmonary fibrosis, which suggests it be viewed as a novel therapeutic target for the treatment of lung fibrosis.




\section{Cellular Physiology Cell Physiol Biochem 2020;54:195-210 \\ \begin{tabular}{ll|l} 
and Biochemistry & $\begin{array}{l}\text { DOI: } 10.33594 / 000000214 \\
\text { Published online: 22 February } 2020\end{array}$ & $\begin{array}{l}\text { C } 2020 \text { The Author(s). Published by } \\
\text { Cell Physiol Biochem Press GmbH\&Co. KG }\end{array}$ \\
\hline
\end{tabular} \\ Kim et al.: p90RSK Inhibition Ameliorates Pulmonary Fibrosis}

\section{Introduction}

Pulmonary fibrosis is a respiratory disease marked by lung tissue scarring and consequent breathing problems [1]. Scar formation and the accumulation of excessive fibrous connective tissue causes thickening and stiffening of tissue in and between air sacs, and thus, impede oxygen supply to blood and the ability to breathe [2, 3]. In the majority of pulmonary fibrosis cases, there is no known cause, and in such cases, the disease is referred to as idiopathic pulmonary fibrosis (IPF). It is difficult to predict at disease onset how rapidly the disease will progress in affected individuals. IPF has a mortality rate of $50 \%$ to $70 \%$ at 2 to 5 years after diagnosis [4]. Recently, pirfenidone and nintedanib have been demonstrated to be clinically effective in IPF. Pirfenidone is an anti-fibrotic and antiinflammatory that was developed to treat IPF [5], and at a molecular level has been reported to suppress fibroblast proliferation, TGF- $\beta 1$-induced collagen synthesis, and the productions of the pro-inflammatory cytokines TNF- $\alpha$ and interleukin-1 $\beta$ (IL-1 $\beta$ ) in vitro and in vivo. In a phase III trial, pirfenidone reduced IPF progression [6], but had several adverse effects, which included hepatic dysfunction, gastrointestinal intolerance, skin reactions, weight loss, anorexia, and fatigue. Thus, it has been recommended that patients taking pirfenidone should be carefully monitored, particularly those with severe hepatic or advanced renal dysfunction [7]. On the other hand, nintedanib is a small molecule tyrosine kinase inhibitor that targets vascular endothelial growth factor receptor (VEGFR), fibroblast growth factor receptor (FGFR), and platelet-derived growth factor receptor (PDGFR), which all potentially underlie pulmonary fibrosis [8]. Nintedanib ultimately reduces proliferation, migration, and survival of fibroblasts, and also probably attenuates angiogenesis in lungs [9]. Nintedanib has also been reported to attenuate the histological features of pulmonary fibrosis and the expressions of profibrotic genes in animal models of lung fibrosis. In two replicate phase 3 trials, nintedanib slowed IPF progression as evidenced by smaller annual reductions in forced vital capacity [10]. The most common adverse reactions associated with nintedanib therapy are gastrointestinal events, particularly diarrhea. Caution should be exercised when a VEGFR inhibitor is administered to patients with an increased risk of bleeding or gastrointestinal perforation or to patients at high risk of cardiovascular disease or with known coronary artery disease. In addition, nintedanib is not recommended in patients with moderate or severe liver disease [11]. Notably, these adverse effects frequently lead to permanent treatment discontinuation, and thus, novel IPF therapeutics with no adverse effects are urgently required.

Cytokines and growth factors play major roles as pathogenetic mediators of pulmonary fibrosis [12]. In particular, TGF- $\beta$ is a pivotal pro-fibrotic cytokine that participates in the development of pulmonary fibrosis by inducing cell differentiation, migration, invasion, EMT, and collagen deposition [13]. A recent study demonstrated kaempferol, a nonselective pharmacological inhibitor of p90RSK, inhibited liver diseases characterized by advanced fibrosis, and thus, suppressed hepatic collagen deposition and the hepatic expressions of profibrotic genes [14]. However, the roles played by p90RSK in TGF- $\beta$ signaling and in the pathogenesis of pulmonary fibrosis have not been determined. It has been reported that many profibrotic growth factors such as CTGF, PDGF and FGF and their kinase signaling cascades contribute to the pathogenesis of fibrotic lung diseases [15]. In fact, it has been reported inhibition of MEK1/2-ERK1/2-p90RSK signaling pathway reduced PDGF-induced cell migration [16]. In addition, FGF-2, a potent fibroblast mitogen, induced collagen synthesis in lung fibroblasts and myofibroblasts, and ERK1/2 inhibition suppressed FGF-induced DNA synthesis and the phosphorylations of ERK1/2 and p90RSK [17]. Furthermore, VEGF caused the rapid activations of Raf-1, MAPK, and p90RSK in cardiac myocytes and fibroblasts [18]. Collectively these findings imply that kinases including p90RSK present a therapeutic target in pulmonary fibrosis.

p90-kDa ribosomal S6 kinase (p90RSK) is a member of the serine/threonine kinase family and is activated by the extracellular signal-regulated kinase (ERK) signaling pathway. p90RSK is known to be involved in numerous signal transductions and to regulate diverse 


\section{Cellular Physiology Cell Physiol Biochem 2020;54:195-210 and Biochemistry Published online: 22 February $2020 \mid \begin{array}{ll}\mathrm{O} 2020 \\ \text { Cell Physiol Biochem Press GmbH\&Co. KG }\end{array}$ \\ Kim et al.: p90RSK Inhibition Ameliorates Pulmonary Fibrosis}

cellular processes including cell proliferation, growth, apoptosis, and transformation [19]. FMK (a fluoromethylketone) inhibits p90RSK by targeting the unique presence of threonine and cysteine residues at two defined positions (Thr493 and Cys436) within the active site of the C-terminal kinase domain of p90RSK $[20,21]$. FMK also irreversibly inhibits the C-terminal kinase activities of RSK1 and RSK2 (RSK isoforms) with remarkable specificity. However, nothing is known of the effect of p90RSK on TGF- $\beta 1$ signaling or of its involvement in the pathogenesis of pulmonary fibrosis, and thus, we undertook to investigate the involvements of p90RSK in these processes.

\section{Materials and Methods}

\section{Cell culture}

To determine the role of p90RSK in controlling TGF- $\beta$-induced fibrosis, we used in vitro model system with lung fibroblasts and alveolar epithelial cells. Human lung fibroblasts (HLFs) and A549 cells (a human alveolar epithelial cell line) were obtained from ATCC. HLF cells were cultured in Dulbecco's modified essential medium (DMEM, HyClone, Logan, UT, USA) supplemented with $10 \% \mathrm{FBS}, 50 \mathrm{U} / \mathrm{mL}$ penicillin, and $50 \mathrm{~g} / \mathrm{mL}$ streptomycin. A549 cells were cultured in F12-K medium (GIBCO) supplemented with $10 \% \mathrm{FBS}, 50 \mathrm{U} / \mathrm{mL}$ penicillin, and $50 \mathrm{~g} / \mathrm{mL}$ streptomycin. Cells were incubated in a humidified $5 \% \mathrm{CO}_{2}$ atmosphere at $37^{\circ} \mathrm{C}$. To examine the epithelial-to-mesenchymal transition (EMT), A549 cells were treated with an increasing concentration of FMK $(2,5,10 \mu \mathrm{M})$ for 1 hour before incubation with $2 \mathrm{ng} / \mathrm{mL}$ TGF- $\beta 1$ for 48 hours and collecting cells were applied to Western blotting analysis and quantitative real time RTPCR for EMT-related genes, such as E-cadherin and N-cadherin. Roles of myofibroblast differentiation and extracellular matrix (ECM) molecule accumulation in controlling TGF- $\beta$-induced pulmonary fibrosis have been established in lung fibroblasts. To examine the ECM and markers of myofibroblast differentiation, HLFs were treated with an increasing concentration of FMK $(2,5,10 \mu \mathrm{M})$ for 1 hour and then incubated with TGF- $\beta 1$ ( $2 \mathrm{ng} / \mathrm{ml})$ for 24 hours. Collecting cells were applied to Western blotting analysis and quantitative real time RT-PCR for ECM and myofibroblast differentiation-related genes, such as $\alpha$-SMA, Calponin, SM $22 \alpha$, Collagen, and Fibronectin.

\section{Reagents and antibodies}

Recombinant TGF- $\beta 1$ was obtained from R\&D systems (Wiesbaden Norderstedt, Germany). FMK, a specific p90RSK inhibitor, was purchased from Axon Medchem (Groningen, Netherlands). Bleomycin and dimethyl sulfoxide (DMSO) were from Sigma (St. Louis, MO, USA). Antibodies were purchased from the following vendors: ERK1/2, p-ERK1/2, p-p90RSK, p-Smad3, and N-cadherin (Cell Signaling Technology, Danvers, MA, USA); lamin B and Smad3 (Invitrogen, Carlsbad, CA, USA); fibronectin, RSK1, E-cadherin, SM22 $\alpha$ (Santa Cruz, Delaware, CA); collagen type I (Millipore, Billerica, MA, USA); collagen type III (Fitzgerald, Acton, MA, USA); and tubulin (Sigma, St. Louis, MO).

Transcriptional response assays

Assays were conducted using the reporter plasmids pSBE-luc or p800-Luc containing the promoter of smad binding elements or PAI-1, respectively. For transcriptional assays of Smad3, cells were transiently co-transfected with the luciferase reporter plasmids (pSBE-Luc or p800-Luc) and pRL-tk. Transfection efficiencies were normalized versus renilla luciferase activities derived from pRL-tk construct, as described previously [22]. Luciferase activities were assessed in cell lysates using a Dual luciferase reporter assay kit (Promega, Madison, WI, USA) and a Glomax 20/20 luminometer (Promega Madison, WI, USA).

\section{Adenoviral vector and transduction}

Ad-DN-p90RSK was used to investigate the effect of p90RSK on the TGF- $\beta 1 /$ Smad signaling pathway. Adenoviral vector encoding a dominant negative form of p90RSK (K94A/K447A, Ad-DN-p90RSK) was used as previously described [23]. HLFs were transduced with adenoviruses at a multiplicity of infection (MOI) of 1 or 10 for 24 hours in growth medium and then treated with or without TGF- $\beta 1$. 


\section{Cellular Physiology Cell Physiol Biochem 2020;54:195-210 \\ \begin{tabular}{l|l|l}
\hline DOI: 10.33594/000000214 & C 2020 The Author(s). Published by
\end{tabular} \\ \begin{tabular}{l|l} 
Published online: 22 February 2020 & Cell Physiol Biochem Press GmbH\&Co. KG \\
\hline
\end{tabular} \\ Kim et al.: p90RSK Inhibition Ameliorates Pulmonary Fibrosis}

\section{Western blot analysis}

Cells were lysed with RIPA lysis buffer supplemented with $1 \mathrm{mM}$ PMSF and $0.01 \mathrm{mM}$ PIC, incubated on ice for 15 minutes, and centrifuged at $15,000 \mathrm{~g}$ for 10 minutes at $4^{\circ} \mathrm{C}$. Protein concentrations in supernatants were determined using a Bradford assay. Proteins were separated by SDS-PAGE (sodium dodecyl sulfatepolyacrylamide gel electrophoresis) and transferred to PVDF (polyvinylidene difluoride) membranes, which were immunoblotted with primary antibodies (1:1000) as indicated in figures and then with corresponding secondary antibodies (1:5000). Signals were visualized using chemiluminescence detection regents (ECL; Millipore, Billerica, MA) according to the manufacturer's instructions.

\section{Assays of Smad3 translocation}

Cellular localizations of Smad3 were determined by Western blot of cytosolic and nuclear protein fractions. Briefly, cells were lysed with lysis buffer A $(10 \mathrm{mM}$ HEPES, $10 \mathrm{mM} \mathrm{KCl,} 0.1 \mathrm{mM}$ EDTA, $0.1 \mathrm{mM}$ EGTA, $1 \mathrm{mM}$ DTT, $1 \mathrm{mM}$ PMSF), incubated on ice for 20 minutes, and centrifuged (15,000 g for 2 minutes at $\left.4^{\circ} \mathrm{C}\right)$. Supernatants represented cytosolic compartments. Pellets were treated with lysis buffer B $(20 \mathrm{mM}$ HEPES, 0.4M NaCl, 1 mM EDTA, 1 mM EGTA, 1 mM DTT, 1 mM PMSF) and centrifuged for 10 minutes. The supernatants obtained from pellets were taken to represent nuclear compartments. Cellular locations of Smad3 were determined by immunoblotting cytosolic and nuclear compartments with Smad3 antibody. Adequate separations of cytosolic and nuclear compartments were confirmed using specific antibodies against tubulin and lamin $B$, respectively.

\section{Immunofluorescence imaging}

Cells pretreated with or without FMK and then with TGF- $\beta 1$ ( $2 \mathrm{ng} / \mathrm{ml}$ ) were fixed in $10 \%$ buffered paraformaldehyde for 30 minutes and permeabilized for 5 minutes at room temperature. Cells were then blocked with 5\% normal goat serum in PBS-0.05\% Tween-20 (PBS-T), incubated with anti-Smad3 antibody (1:100) overnight at $4^{\circ} \mathrm{C}$, with FITC-conjugated anti-mouse IgG (Invitrogen, Carlsbad, CA, USA) for 90 minutes, and counter-stained with DAPI (4,6-diamidino-2-phenylindole) for 10 minutes at room temperature. Signals were observed and recorded using a confocal microscope (Leica, Bannockbum, IL, USA).

\section{$R T-q P C R$}

Expression levels of mRNAs were measured by quantitative real time RT-PCR (RT-qPCR) as described previously [24]. Briefly, total RNA was isolated using TRIzol@ Reagent (Invitrogen, Carlsbad, CA, USA), and reverse transcription was conducted using TaqMan reverse transcription reagents (Applied Biosystems, Carlsbad, CA) according to the manufacturer's instructions. RT-qPCR was conducted using $1 \mu$ l of template cDNA and Power SYBR Green (Applied Biosystems, Carlsbad, CA) in an ABI PRISM 7500 unit (Applied Biosystems, Carlsbad, CA). Quantification was conducted using the efficiency-corrected $\Delta \Delta \mathrm{Cq}$ method. The primers used to amplify DNA sequences were as follows:

human PAI-1 forward 5'-CCCTTTGCAGGATGGAACTA-3'

and reverse 5'-ATGGCAATGTGACTGGAACA-3',

human Fibronectin forward 5'-AAGGTTCGGGAAGAGGTTGT-3'

and reverse 5'-CGAGTCATCCGTAGGTTGGT-3',

human E-cadherin forward 5'-GGCCTGAAGTGACTCGTAACGA-3'

and reverse 5' - CAGCCGCTTTCAGATTTTCATC-3',

human N-cadherin forward 5'-TCAGTGGCGGAGATCCTACT-3'

and reverse 5'-TGGTTTGACCACGGTGACTA-3',

GAPDH forward 5'-GGAGCCAAAAGGGTCATCAT-3'

and reverse 5'-GTGATGGCATGGACTGTGGT-3'.

\section{Mouse and animal experiments}

Specific pathogen free C57BL/6 mice were purchased from Samtaco (Seoul, Republic of Korea). Male mice (25-30 g body weight) were intratracheally (i.t.) inoculated with bleomycin ( 0.75 unit/kg body weight in $50 \mu \mathrm{L}$ saline) to induce pulmonary fibrosis. To determine in vivo anti-fibrotic effect of FMK, mice were inoculated with bleomycin with or without FMK treatment and sacrificed 3 and 5 days (for WB analysis) and 14 days (for histological analysis) after BLM inoculation. In each experiment, 5 mice in each group 


\section{Cellular Physiology Cell Physiol Biochem 2020;54:195-210 \\ \begin{tabular}{ll|ll} 
and Biochemistry & $\begin{array}{l}\text { DOl: 10.33594/000000214 } \\
\text { Published online: 22 February } 2020\end{array}$ & $\begin{array}{l}\text { O 2020 The Author(s). Published by } \\
\text { Cell Physiol Biochem Press GmbH\&Co. KG }\end{array}$ \\
\cline { 2 - 3 } &
\end{tabular} \\ Kim et al.: p90RSK Inhibition Ameliorates Pulmonary Fibrosis}

was inoculated. Experiments were repeated two times and representative data are presented. To determine the in vivo effect of FMK (a specific p90RSK inhibitor) on pulmonary fibrosis, FMK was i.p. administrated to mice at $5 \mathrm{mg} / \mathrm{kg}$ every other day for 2 weeks. Vehicle controls were administered dimethyl sulfoxide in the same manner. Protein was extracted from lung tissues, and levels of collagen type I, III, fibronectin, p-p90RSK, p90RSK, p-Smad3, smad3, and tubulin were assessed by Western blot. In addition, lung tissues were fixed in $10 \%$ buffered formaldehyde, paraffin embedded, and $5 \mu \mathrm{m}$ thick sections were immunostained with p-p90RSK immunohistochemical staining, or stained with H\&E (hematoxylin and eosin) or Masson's trichrome (MTC). Positive signals of p-p90RSK in lung tissue sections stained with p-p90RSK antibody were measured with Fiji ImageJ2 software (NIH, MD, USA) and expressed as optical densities of positive signal $(n=4)$. The quantitative histological analysis of lung fibrosis was performed by measuring the alveolar air area in $\mathrm{H} \&$ E stained lung tissues $(n=4)$ using ImageJ version 1.52q (NIH, MD, USA) and expressed as the percentage of alveolar air area. The quantification of collagen-positive areas in Masson Trichrome stained lung tissues $(n=4)$ were performed using Image J version $1.52 \mathrm{q}(\mathrm{NIH}, \mathrm{MD}, \mathrm{USA})$ and expressed as the percentage of collagen positive area. All animal experiments were approved by the Institutional Animal Care and Use Committee of Yeungnam University College of Medicine. All experiments were carried out in accordance with the approved guidelines.

\section{Statistical analysis}

The significances of intergroup differences were determined using the Student's $t$-test and multiple group comparisons using ANOVA followed by Bonferroni's post hoc test. Results are presented as the means \pm SDs of three independent experiments. The analysis was conducted using GraphPad prism Ver. 5.0 (Graph-Pad Software Inc.), and $p$ values of $<0.05$ were considered statistically significant.

\section{Results}

p90RSK mediated TGF- $\beta 1$-induced epithelial-to-mesenchymal transition

It has been reported that the induction of epithelial-to-mesenchymal transition (EMT) by TGF- $\beta 1$ is a key event in pulmonary fibrosis [25]. To determine the effect of p90RSK on TGF- $\beta 1$-induced EMT-related gene expressions, p90RSK was pharmacologically inhibited with FMK or with adenovirus encoding a dominant negative form of p90RSK (Ad-DNp90RSK). It is known E-cadherin is a specific marker of epithelial cells, and that N-cadherin is specific marker of mesenchymal cells [26]. Biochemical data showed that FMK markedly and concentration-dependently inhibited the TGF- $\beta 1$-mediated down-regulation of E-cadherin and the up-regulation of N-cadherin (Fig. 1A). Similarly, Ad-DN-p90RSK significantly inhibited the TGF- $\beta 1$-mediated down-regulation of E-cadherin and up-regulation of $\mathrm{N}$-cadherin (Fig. 1B). In addition, both FMK and Ad-DN-p90RSK suppressed the TGF- $\beta 1$-induced downregulation of E-cadherin mRNA expression and the up-regulation of $\mathrm{N}$-cadherin mRNA expression in A549 cells (Fig. 1C, D). These observations suggest that inhibition of p90RSK blocks TGF- $\beta 1$-mediated EMT.

\section{p90RSK regulated TGF- $\beta 1$-induced myofibroblast differentiation}

Roles of myofibroblast differentiation and extracellular matrix (ECM) molecule accumulation in controlling TGF- $\beta$-induced pulmonary fibrosis have been established in lung fibroblasts [27]. By considering the critical roles of lung fibroblasts in pathophysiology of lung fibrosis, we investigated whether p90RSK affects TGF- $\beta 1$-induced specific markers of myofibroblast differentiation in human lung fibroblasts (HLFs). Biochemical data showed that FMK significantly and concentration-dependently inhibited the TGF- $\beta 1$-induced protein expressions of $\alpha$-SMA, calponin, and SM22 $\alpha$ (Fig. 2A). Similarly, Ad-DN-p90RSK markedly inhibited TGF- $\beta 1$-induced protein expressions of $\alpha$-SMA, calponin, and SM22 $\alpha$ (Fig. 2B). These observations suggest p90RSK inhibition blocks TGF- $\beta 1$-mediated pulmonary fibrosis by preventing myofibroblast differentiation. 


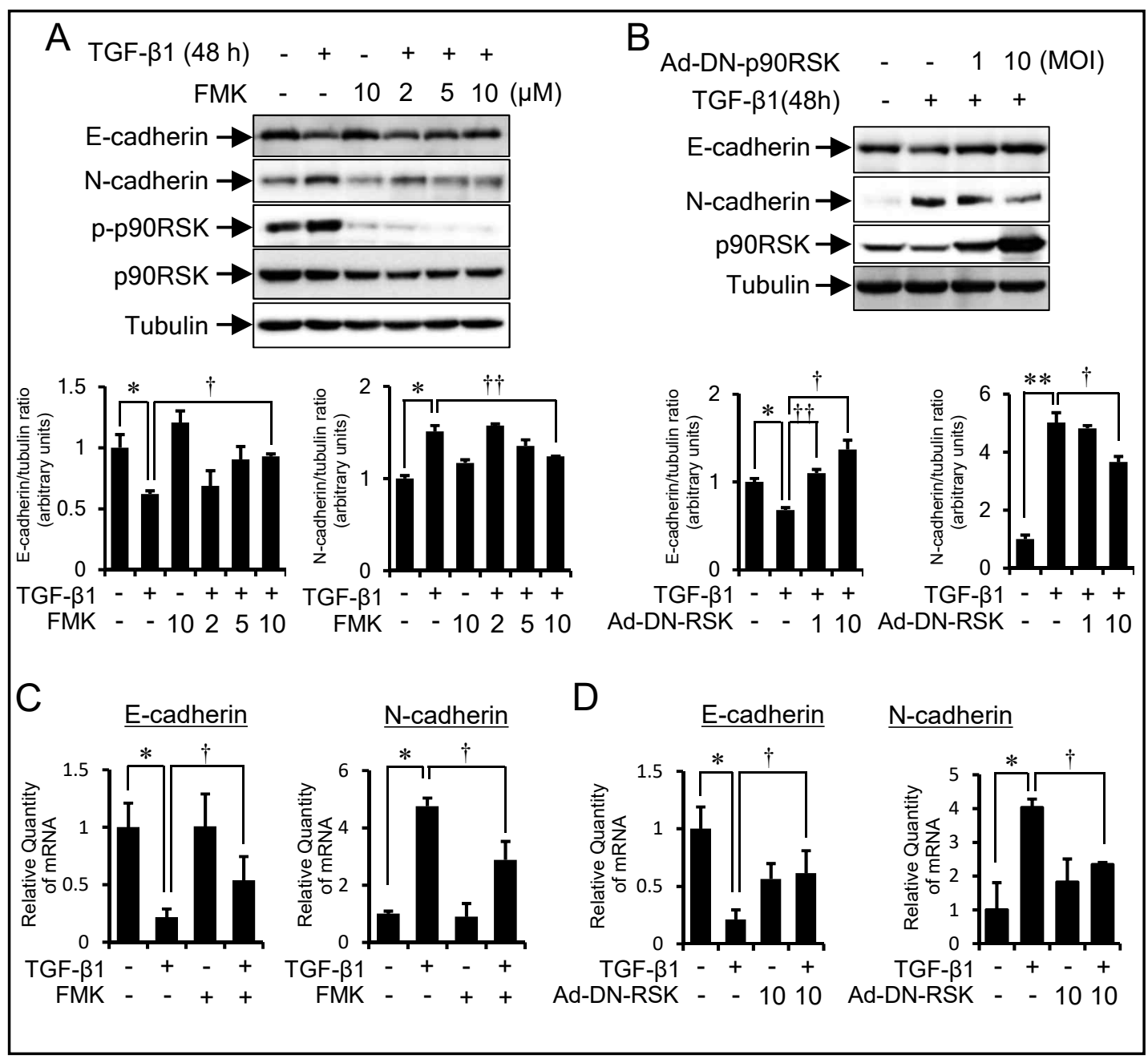

Fig. 1. p90RSK mediated TGF- $\beta 1$-induced epithelial-to-mesenchymal transition. A: A549 lung epithelial cells were treated with increasing concentrations of FMK for 1 hour and incubated with TGF- $\beta 1(2 \mathrm{ng} / \mathrm{ml})$ for 48 hours. Levels of E-cadherin, N-cadherin, p-p90RSK, and p90RSK were analyzed by immunoblotting. Bar graphs present the densitometric results of Western blot bands. ANOVA: ${ }^{*}, \mathrm{p}<0.05$ versus CON. ${ }^{\dagger}, \mathrm{p}<0.05$, ${ }^{\dagger}, \mathrm{p}<0.01$ versus TGF- $\beta 1$ treated. B: A549 cells were transduced with Ad-DN-RSK or Ad-LacZ for 1 day and then treated with TGF- $\beta 1$ ( $2 \mathrm{ng} / \mathrm{ml}$ ) for 48 hours. Protein levels were analyzed by immunoblotting using specific antibodies against E-cadherin, N-cadherin, p-p90RSK, p90RSK, and tubulin. Bar graphs present the densitometric results of Western blot bands. ANOVA: ${ }^{*}, \mathrm{p}<0.05 ;{ }^{* *}, \mathrm{p}<0.01$ versus CON. ${ }^{\dagger}, \mathrm{p}<0.05,{ }^{+\dagger}$, p $<0.01$ versus TGF- $\beta 1$ treated. C: A549 cells were pretreated with $10 \mu \mathrm{M}$ FMK for 1 hour and then incubated with TGF- $\beta 1$ ( $2 \mathrm{ng} / \mathrm{ml}$ ) for 48 hours. The mRNA levels of E-cadherin and N-cadherin were determined by RT-qPCR. D: A549 cells were transduced with Ad-DN-RSK or Ad-LacZ for 1 day and treated with TGF- $\beta 1$ ( $2 \mathrm{ng} / \mathrm{ml}$ ) for 48 hours. The mRNA levels of E-cadherin and N-cadherin were determined by RT-qPCR. Relative expression levels were normalized versus GAPDH. Results are presented as the means \pm SDs of three independent experiments that produced similar results $\left(^{*}, \mathrm{p}<0.05\right.$ versus $C O N .{ }^{\dagger}, \mathrm{p}<0.05,{ }^{\dagger}, \mathrm{p}<0.01$ versus TGF- $\beta 1$ treated.). 


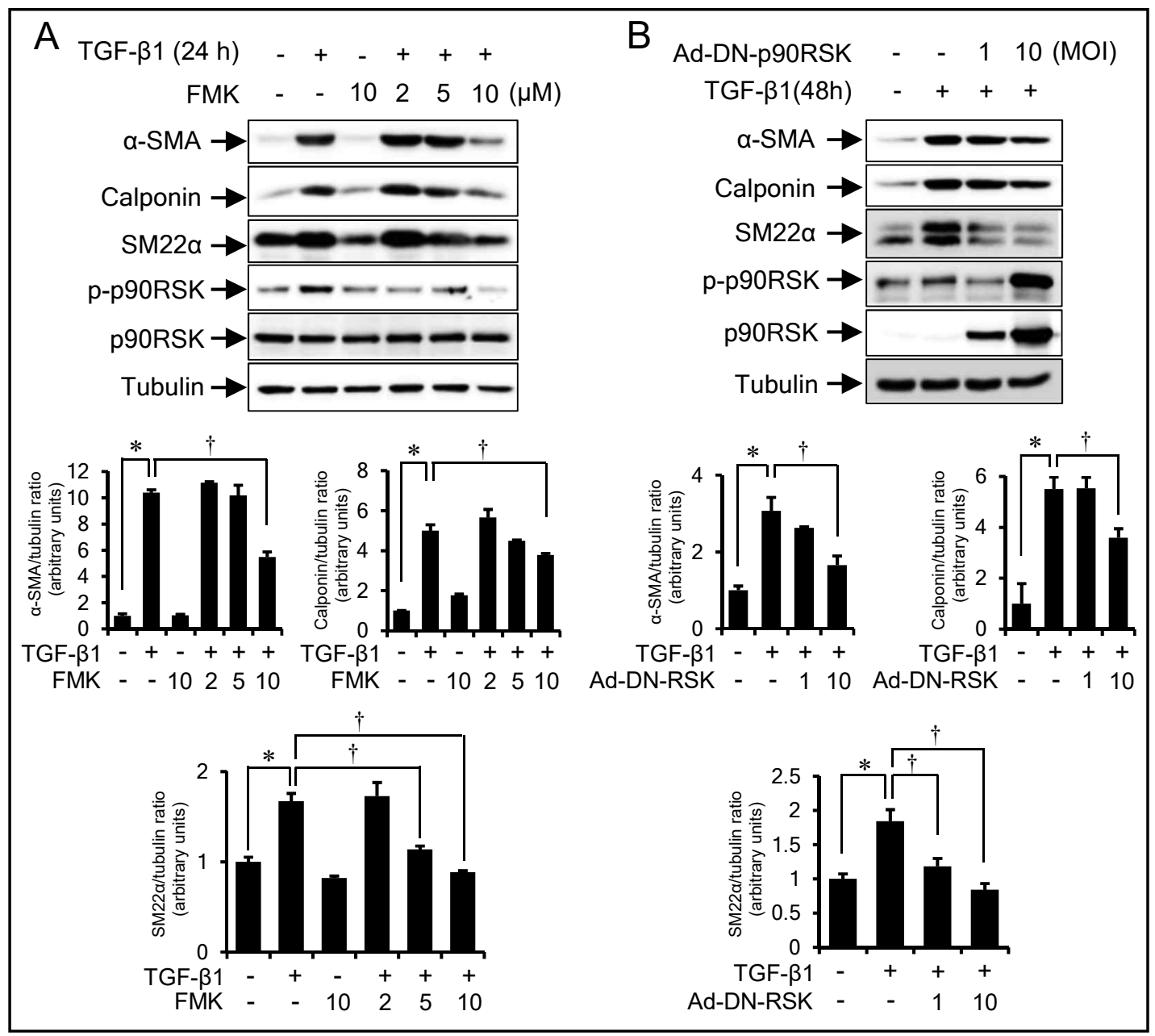

Fig. 2. p90RSK regulated TGF- $\beta 1$-induced myofibroblast differentiation. A: Human lung fibroblasts were treated with increasing concentrations of FMK for 1 hour and then incubated with TGF- $\beta 1$ ( $2 \mathrm{ng} / \mathrm{ml})$ for 24 hours. $\alpha$-SMA, calponin, SM22 $\alpha$, p-p90RSK, p90RSK, and tubulin protein levels were assessed by immunoblotting. Bar graphs present the densitometric results of Western blot bands. ANOVA: ${ }^{*}, \mathrm{p}<0.05$; ${ }^{* *}$, $\mathrm{p}<0.01$ versus $\operatorname{CON} .{ }^{\dagger}, \mathrm{p}<0.05,{ }^{\dagger}, \mathrm{p}<0.01$ versus TGF- $\beta 1$ treated. B: Human lung fibroblasts were transduced with Ad-DN-RSK or Ad-LacZ for 1 day and treated with TGF- $\beta 1$ (2 ng/ml) for 24 hours. Protein levels were assessed by immunoblotting with specific antibodies against $\alpha$-SMA, calponin, SM22 $\alpha$, p-p90RSK, p90RSK, and tubulin. Bar graphs represent the densitometric results of western blot bands. Results are presented as the means \pm SDs of three independent experiments. $\left(*, p<0.05\right.$ versus CON. ${ }^{\dagger}, \mathrm{p}<0.05,{ }^{+\dagger}, \mathrm{p}<0.01$ versus TGF- $\beta 1$ treated. $(n=3)$.

\section{p90RSK was involved in TGF- $\beta 1$-induced ECM accumulation}

The role played by p90RSK in TGF- $\beta 1$-induced expressions of ECM molecules were examined in HLFs. FMK pretreatment significantly inhibited the TGF- $\beta 1$-induced protein expressions of type 3 collagen and fibronectin in fibroblasts (Fig. 3A). Similarly, TGF- $\beta 1$ induced protein expressions of type 3 collagen and fibronectin were also markedly inhibited in HLFs transduced with Ad-DN-p90RSK (Fig. 3B). In addition, the TGF- $\beta 1$-induced mRNA expressions of fibronectin and PAI-1 were also significantly inhibited by FMK (Fig. 3C). These results show p90RSK promotes the TGF- $\beta 1$-induced expressions of ECM and profibrotic genes. 


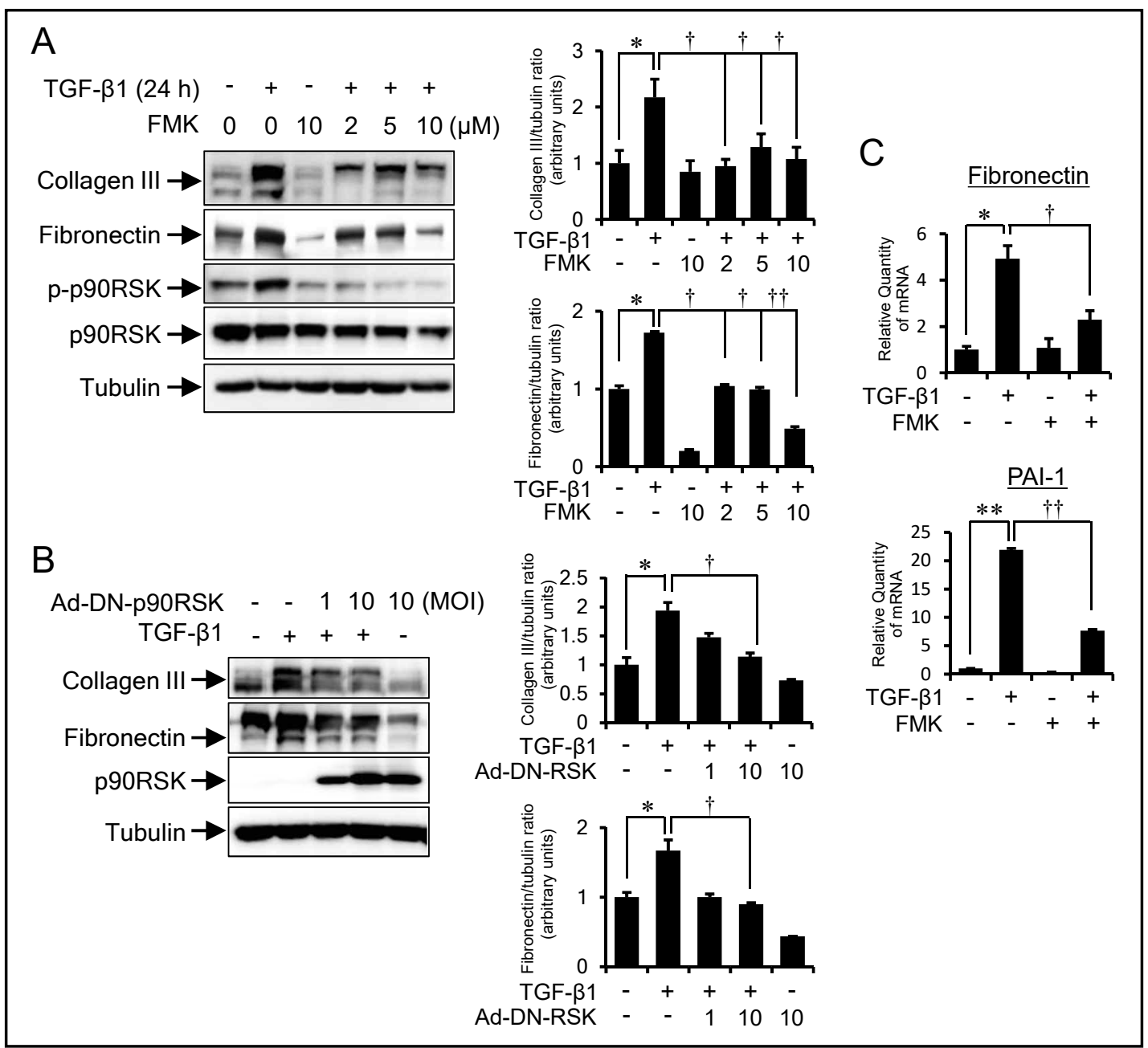

Fig. 3. p90RSK was involved in TGF- $\beta 1$-induced ECM accumulation. A: Human lung fibroblasts were treated with increasing concentrations of FMK for 1 hour and then incubated with TGF- $\beta 1$ ( $2 \mathrm{ng} / \mathrm{ml})$ for 24 hours. Protein levels were assessed by immunoblotting with specific antibodies against collagen III, fibronectin, p-p90RSK, p90RSK, and tubulin. Bar graphs present the densitometric results of Western blot bands. ANOVA: ${ }^{*}, \mathrm{p}<0.05 ;{ }^{* *}, \mathrm{p}<0.01$ versus CON. ${ }^{\dagger}, \mathrm{p}<0.05,{ }^{\dagger \dagger}, \mathrm{p}<0.01$ versus TGF- $\beta 1$ treated. B: Fibroblasts were transduced Ad-DN-RSK or Ad-LacZ for 1 day and then treated with TGF- $\beta 1$ ( $2 \mathrm{ng} / \mathrm{ml}$ ) for 24 hours. Expression levels of collagen III, fibronectin, p90RSK and tubulin were assessed by Western blotting. Bar graphs present the densitometric results of Western blot bands. ANOVA: ${ }^{*}, \mathrm{p}<0.05 ;{ }^{* *}, \mathrm{p}<0.01$ versus CON. ${ }^{\dagger}, \mathrm{p}<0.05,{ }^{\dagger+}, \mathrm{p}<0.01$ versus TGF- $\beta 1$ treated. C: Fibroblasts were treated with $10 \mu \mathrm{M}$ FMK in the presence of TGF- $\beta 1$ ( $2 \mathrm{ng} / \mathrm{ml})$ for 6 hours. The mRNA levels of fibronectin and PAI-1 were determined by RT-qPCR. Relative expression levels were normalized versus GAPDH. Results are presented as the means \pm SDs of three independent experiments that produced similar results. *: $\mathrm{p}<0.05 ;{ }^{* *}$ : $<<0.01$.

\section{p90RSK inhibition did not influence the TGF- $\beta 1$-induced C-terminal phosphorylation of} Smad3

To further elucidate the molecular mechanisms underlying the p90RSK-mediated regulation of TGF- $\beta 1$-induced fibrogenic responses, we evaluated the effect of p90RSK inhibition on TGF- $\beta 1$-induced Smad3 activation in HLFs. Interestingly, neither FMK pretreatment (Fig. 4A) nor Ad-DN-p90RSK transduction (Fig. 4B) inhibited TGF- $\beta 1$-induced Smad3 phosphorylation. As expected, TGF- $\beta 1$-induced ERK1/2 phosphorylation was not affected by FMK and Ad-DN-RSK, suggesting that p90RSK may act as a downstream of ERK1/2. 


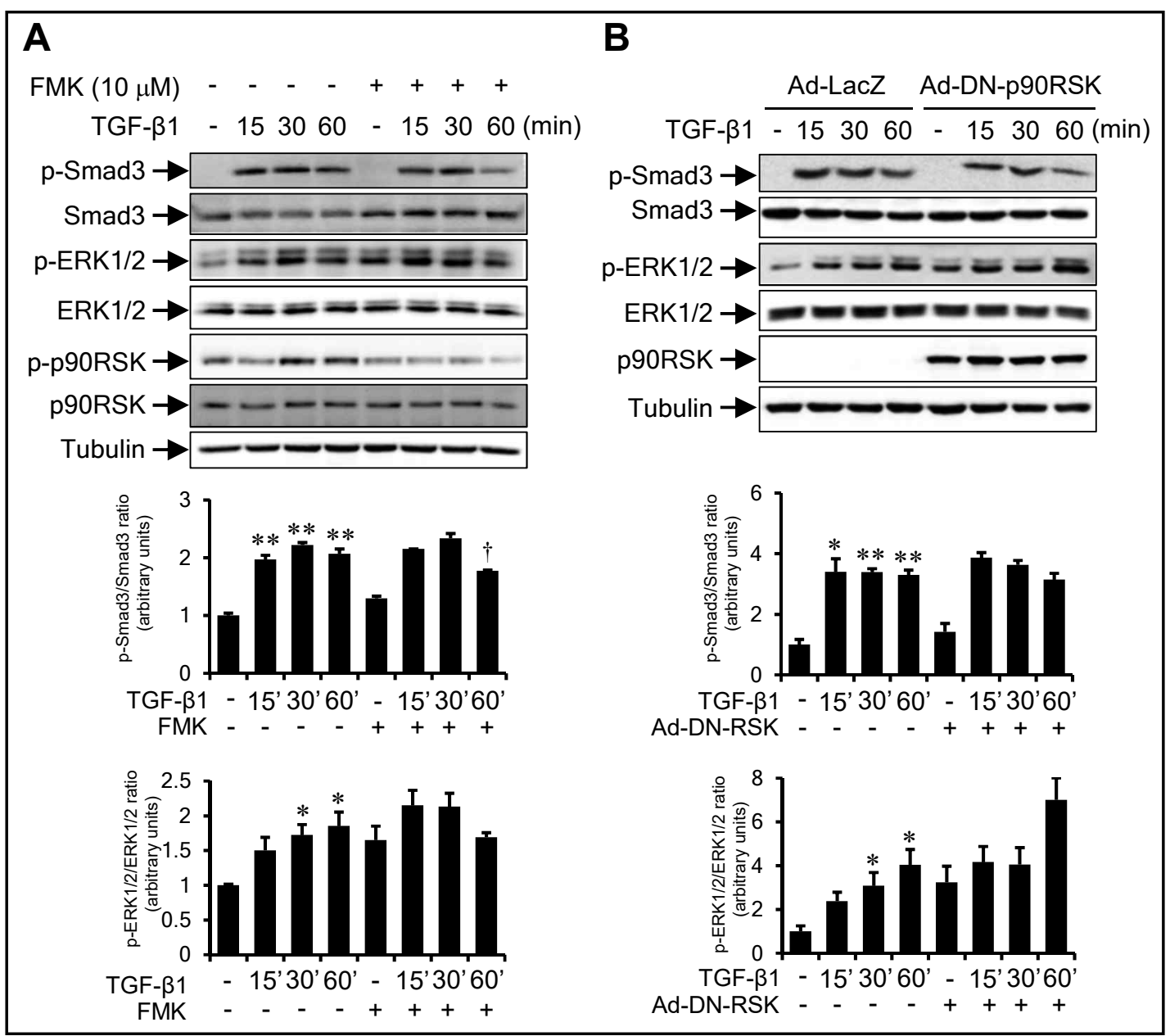

Fig. 4. p90RSK did not affect C-terminal phosphorylation of Smad3 in response to TGF- $\beta 1$. A: Human lung fibroblasts were treated with $10 \mu \mathrm{M}$ FMK for 1 hour and then incubated with TGF- $\beta 1$ ( $2 \mathrm{ng} / \mathrm{ml})$ for 15,30 , or 60 minutes. Cell lysates were immunoblotted with antibodies of p-Smad3, Smad3, p-ERK1/2, ERK1/2, p-p90RSK, p90RSK, and tubulin. Bar graphs present the densitometric results of Western blot bands. ANOVA: *, $\mathrm{p}<0.05$; **, $\mathrm{p}<0.01$. B: Fibroblasts transduced with Ad-DN-RSK or Ad-Lacz were treated with TGF- $\beta 1$ (2 $\mathrm{ng} / \mathrm{ml}$ ) for 15, 30, or 60 minutes, and cell lysates were immunoblotted using p-Smad3, Smad3, p-ERK1/2, ERK1/2, p90RSK, and tubulin antibodies. Bar graphs represent densitometric results of western blot bands. Results are presented as the means \pm SDs of three independent experiments. ${ }^{*}, \mathrm{p}<0.05 ;{ }^{* *}, \mathrm{p}<0.01(\mathrm{n}=3)$.

p90RSK did not regulate the TGF- $\beta 1$-induced nuclear translocation of Smad3

To determine whether p90RSK regulates TGF- $\beta 1$-Smad3 cascade by regulating the nuclear translocation of Smad3 in HLFs, we performed immunofluorescence staining for Smad3 and Western blot analysis of cytosolic and nuclear protein fractions (Fig. 5). FMK pretreatment did not inhibit the TGF- $\beta 1$-induced nuclear translocation of Smad3, indicating that p90RSK inhibition did not suppress the TGF- $\beta 1$-induced nuclear translocation of Smad3 and p90RSK may regulate TGF- $\beta 1$-mediated Smad3 signaling in downstream events after nuclear translocation. 


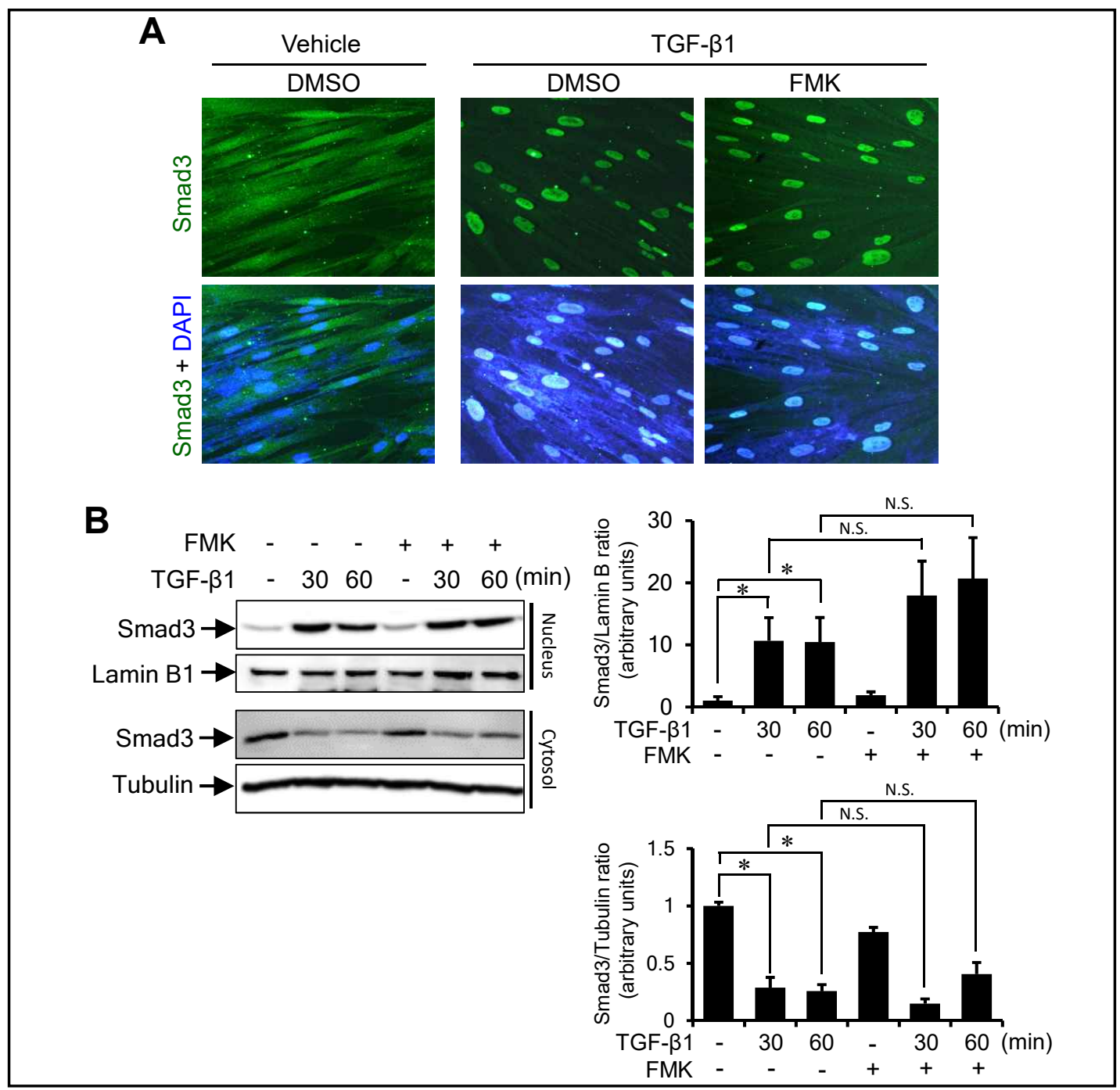

Fig. 5. p90RSK was not involved in TGF- $\beta 1$-induced nuclear translocation of Smad3. A: Human lung fibroblasts were incubated with $10 \mu \mathrm{M}$ FMK for 1 hour and then incubated with TGF- $\beta 1$ ( $2 \mathrm{ng} / \mathrm{ml}$ ) for 30 minutes. Cells were stained with anti-Smad3 antibody and nuclei were stained with DAPI. Cells were visualized at x200 under an immunofluorescence microscope (Olympus, Tokyo, Japan). B: Fibroblasts were pretreated with $10 \mu \mathrm{M}$ FMK for 1 hour and then incubated with TGF- $\beta 1$ (2 ng/ml) for 30 or 60 minutes. Nuclear and cytosol compartments were obtained by cellular fractionation as described in Materials and Methods. Cellular localizations of Smad3 were determined by immunoblotting with anti-Smad3 antibody and specific antibodies of lamin B1 and tubulin. Bar graphs represent densitometric results of Western blot bands. Results are presented as the means \pm SDs of three independent experiments. *: p<0.05; N.S.: not significant $(n=3)$.

\section{Inhibition of p90RSK blocked TGF- $\beta 1$-induced Smad3 transcriptional activation and PAI-1} promoter activity

To determine whether p90RSK affects Smad3 transcriptional activation and PAI1 promoter activity, lung epithelial cells were transiently transfected with pSBE-luc or p800-luc, which contains smad binding elements or PAI-1 promoter, respectively. PAI-1 is a multifunctional glycoprotein that plays an important role in several progressive, chronic fibrotic disorders [28], and TGF- $\beta 1$ is a known inducer of PAI-1. FMK pretreatment inhibited TGF- $\beta 1$-induced SBE-dependent transcriptional activity (Fig. 6A) and PAI-1 promoter activity (Fig. 6B). In addition, Ad-DN-p90RSK attenuated TGF- $\beta 1$ signal to Smad3 transcriptional activity (Fig. 6C) and PAI-1 promoter activity in A549 cells (Fig. 6D). To show the specificity of reporter assay with the TGF- $\beta$ signaling pathway, we used SIS3, a specific inhibitor of 


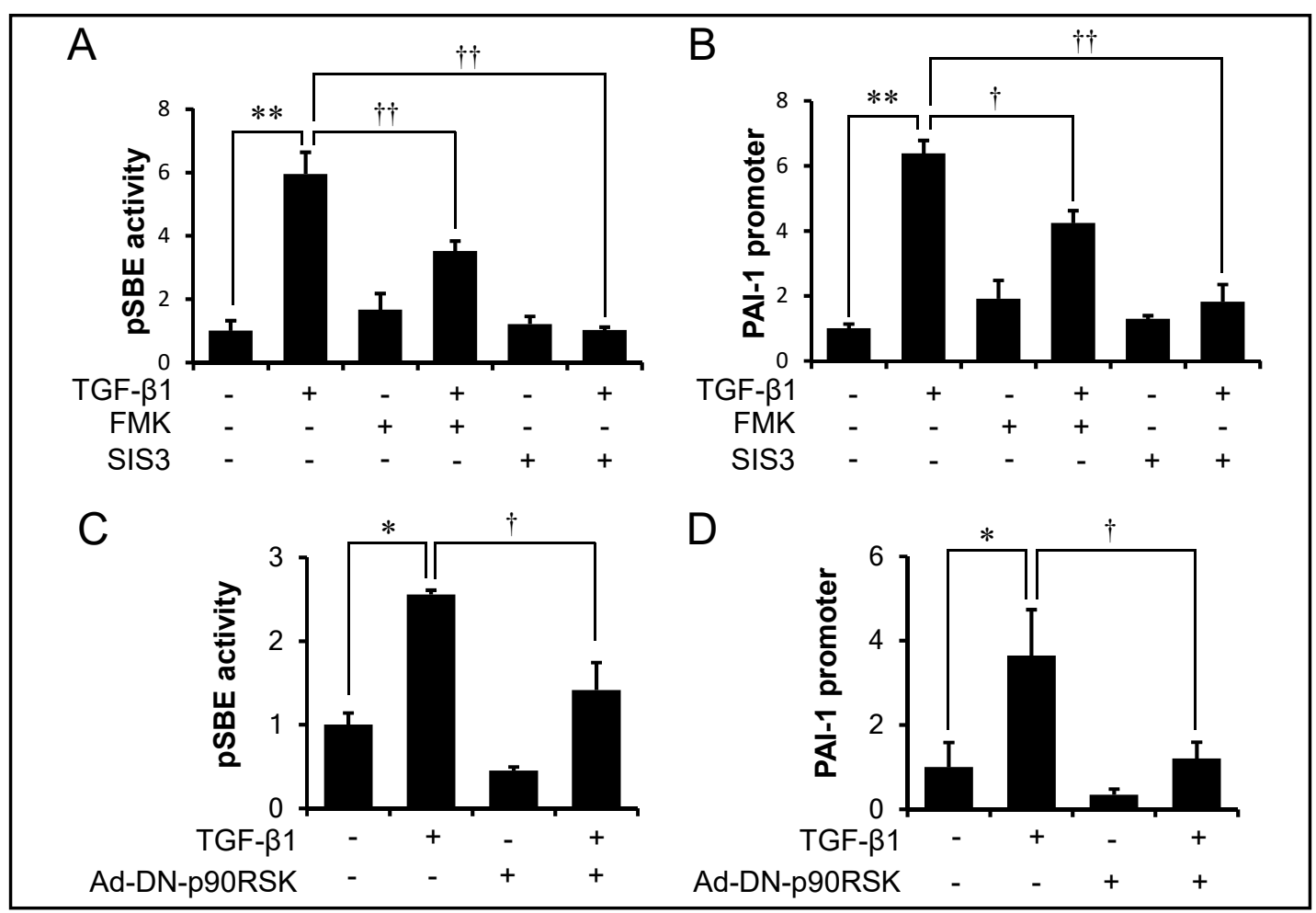

Fig. 6. p90RSK was involved in TGF- $\beta 1$-induced Smad 3 transcriptional activation and PAI-1 promoter activity. A and B: A549 cells were transfected with pSBE-Luc or p800-Luc, which contain smad binding elements or a fragment of PAI-1 promoter, respectively. Transfected cells were pretreated with FMK $(10 \mu \mathrm{M})$ or SIS3, a specific inhibitor of Smad3, and then treated with TGF- $\beta 1$ ( $2 \mathrm{ng} / \mathrm{ml}$ ) for 6 hours. C and D: A549 cells were transduced with Ad-LacZ or Ad-DN-p90RSK, transfected with pSBE-Luc or p800-Luc, and then treated with TGF- $\beta 1(2 \mathrm{ng} / \mathrm{ml})$ for 6 hours. Luciferase activities in cell lysates were measured using the Dual luciferase reporter assay kit and a Glomax 20/20 luminometer. Transfection efficiencies were normalized versus renilla luciferase activity derived from pRL-tk construct. Results are presented as the means \pm SDs of three independent experiments. ${ }^{*}, \mathrm{p}<0.05$; ${ }^{* *}, \mathrm{p}<0.01$ versus $\mathrm{CON} .{ }^{\dagger}, \mathrm{p}<0.05,{ }^{\dagger \dagger}, \mathrm{p}<0.01$ versus TGF- $\beta 1$ treated.

Smad3, as a positive control (Fig. 6A, 6B). These observations suggest p90RSK plays a critical mediating role in the profibrotic responses induced by TGF- $\beta 1$ via the transcriptional activation of Smad3.

Inhibition of p90RSK attenuated pulmonary fibrosis in our mouse model of pulmonary fibrosis

To study the anti-fibrotic effect of p90RSK inhibition in vivo, we first assessed p90RSK activation in lung tissues at 3 or 5 days after bleomycin inoculation in our mouse model of lung fibrosis. p90RSK phosphorylation was greatly increased by administering bleomycin i.t. (Fig. 7A). In addition, immunohistochemical analysis showed more intense staining of p-p90RSK in lung tissues at 14 days after bleomycin administration (Fig. 7B). We then examined the anti-fibrotic effect of FMK in our mouse model of lung fibrosis. FMK pretreatment suppressed the protein expressions of ECM, type 1 and type 3 collagen, and fibronectin in the lung tissues of bleomycin administered mice as compared with vehicle controls (Fig. 7C). Furthermore, FMK markedly suppressed fibrogenic histological changes (Fig. 7D) and collagen accumulation (Fig. 7E) in the lung tissues of the bleomycin model. In addition, areas of consolidated fibrotic patches were greatly increased by bleomycin, but markedly reduced by FMK. Taken together, these results suggest that inhibition of p90RSK suppressed pulmonary fibrosis in vivo. 


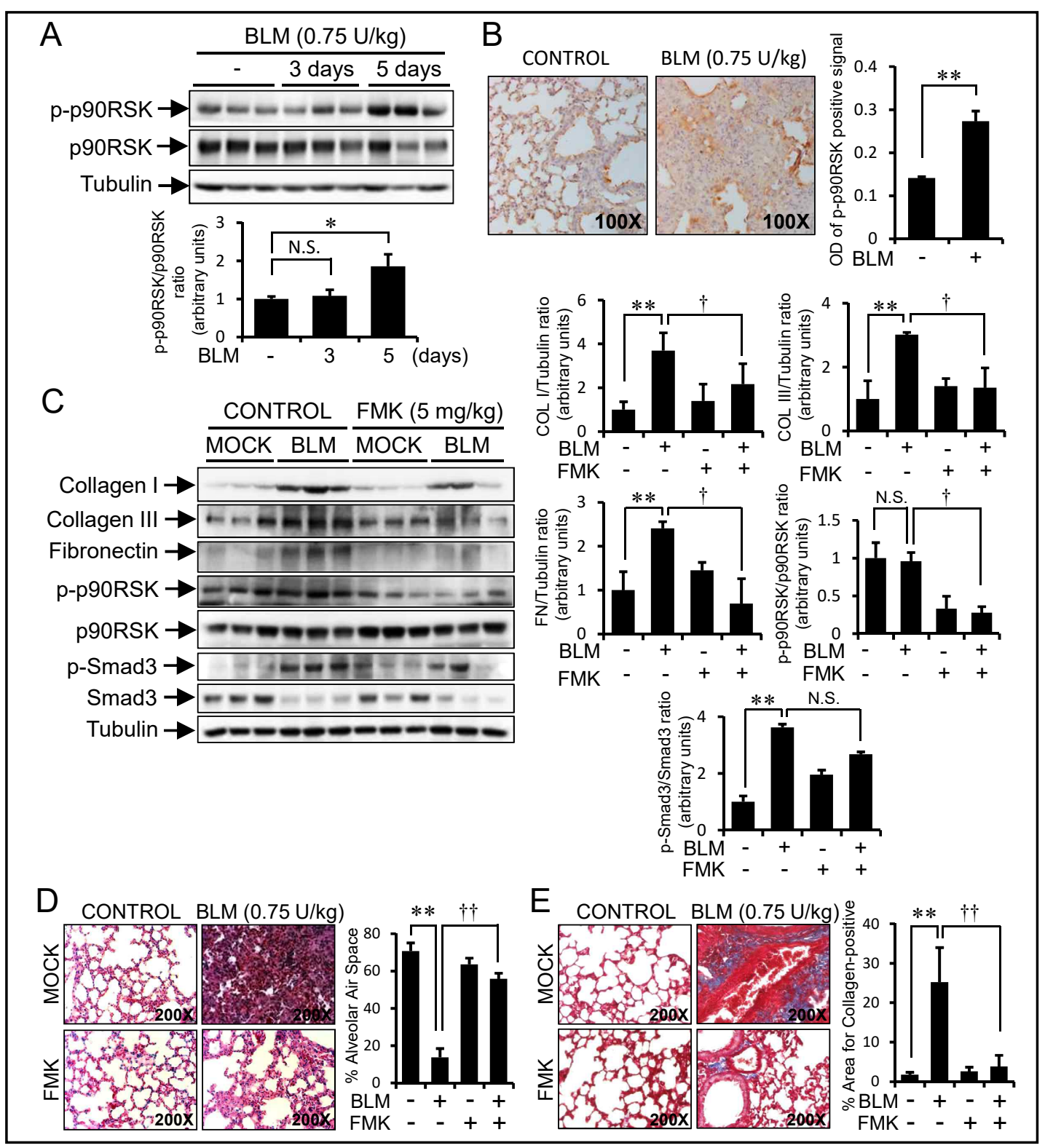

Fig. 7. FMK treatment ameliorated bleomycin-induced lung fibrosis. A: Mice were examined at 3 or 5 days after the intratracheal administration of bleomycin (BLM) as described in the Materials and Methods ( $\mathrm{n}=5)$. Lung tissue lysates were immunoblotted with antibodies for phospho-p90RSK, p90RSK, and tubulin. Bar graphs represent densitometric results of Western blot bands. B: To determine the in vivo effect of FMK (a specific p90RSK inhibitor) on pulmonary fibrosis induced by BLM, FMK was i.p. administrated to mice at $5 \mathrm{mg} / \mathrm{kg}$ every other day for 14 days. Mice were analyzed at 14 days after the intratracheal administration of BLM $(n=5)$. Protein expressions of p-p90RSK in lung tissues were examined by immunohistochemistry. Positive signals of p-p90RSK in lung tissue sections stained with p-p90RSK antibody were measured with Fiji ImageJ2 software (NIH, MD, USA) and expressed as optical densities of positive signal $(n=4)$. Data was presented as the Mean \pm Standard Deviation. C: Mice were analyzed 14 days after BLM intratracheal administration in the presence or absence of FMK i.p. injection, as described in Material and Methods ( $n=5)$. Lung tissue lysates were immunoblotted with antibodies for collagen I, collagen III, fibronectin, p-p90RSK, p90RSK and tubulin. D: Histological sections of lung tissue were stained with hematoxylin and eosin. The quantitative histological analysis of lung fibrosis was performed by measuring the alveolar air area in H \& E stained lung tissues $(n=4)$ using Image J version 1.52q (NIH, MD, USA) and expressed as the percentage of alveolar air area. Data was presented as the Mean \pm Standard Deviation. E: Histological sections of lung tissue were stained with Masson Trichrome. The quantification of collagen-positive areas in Masson Trichrome stained lung tissues $(n=4)$ were performed using ImageJ version 1.52q (NIH, MD, USA) and expressed as the percentage of collagen positive area. Data was presented as the Mean \pm Standard Deviation. *, $\mathrm{p}<0.05$; $^{* *}, \mathrm{p}<0.01$ versus CON. ${ }^{\dagger}, \mathrm{p}<0.05,{ }^{+\dagger}, \mathrm{p}<0.01$ versus TGF- $\beta 1$ treated, N.S.: not significant. 


\section{Cellular Physiology Cell Physiol Biochem 2020;54:195-210 \\ \begin{tabular}{ll|l} 
and Biochemistry & $\begin{array}{l}\text { DOI: 10.33594/000000214 } \\
\text { Published online: 22 February 2020 }\end{array}$ & $\begin{array}{l}\text { C } 2020 \text { The Author(s). Published by } \\
\text { Cell Physiol Biochem Press GmbH\&Co. KG }\end{array}$ \\
\hline
\end{tabular} \\ Kim et al.: p90RSK Inhibition Ameliorates Pulmonary Fibrosis}

\section{Discussion}

The present study was performed to determine whether inhibition of p90RSK suppresses TGF- $\beta 1$-induced EMT, ECM accumulation, and profibrogenic gene expressions in vitro and in vivo. Interestingly, inhibition of p90RSK suppressed TGF- $\beta 1$-induced ECM accumulation, profibrogenic responses, and EMT in HLFs and in A549 lung epithelial cells (Fig. 1, 2, 3). Although p90RSK inhibition significantly reduced TGF- $\beta 1$-induced Smad3 transcriptional activity, TGF- $\beta 1$-stimulated C-terminal phosphorylation and nuclear translocation of Smad3 were found to be unaffected by p90RSK signaling (Fig. 4, 5, 6). Furthermore, in our mouse model of bleomycin-induced lung fibrosis, FMK suppressed the development of pulmonary fibrosis (Fig. 7).

p90RSK has been shown to be involved in diverse cellular processes such as cell proliferation, apoptosis, and transformation and been implicated in atherosclerosis, heart disease and liver disease $[14,23,29]$. In a previous study, the p90RSK-C/EBP $\beta$ phosphorylation pathway was found to be critical for activating hepatic stellate cells during the progression of liver fibrosis [30]. Buck et al. reported that blocking C/EBP- $\beta$-Thr217 phosphorylation by blocking peptide with Thr/Ala mutation inhibited the development of lung fibrosis by inhibiting lung myofibroblast activation [31], and in a recent study, it was demonstrated that kaempferol, a nonselective pharmacological inhibitor of p90RSK, inhibited liver diseases characterized by advanced fibrosis, suppressed hepatic collagen deposition, and the expressions of profibrotic genes [14]. In contrast, little is known about the specific role played by p90RSK in pulmonary fibrosis. In the present study, p90RSK regulated TGF- $\beta 1$ induced ECM accumulation and profibrogenic gene expressions in HLFs and A549 cells (Fig. 1, 2 and 3). In addition, FMK inhibited lung fibrosis in our bleomycin-induced murine model of lung fibrosis (Fig. 7).

TGF- $\beta$ has both canonical Smad-dependent signaling pathway and non-canonical Smadindependent signaling pathway. In Smad-independent pathways, TGF- $\beta$ activates MAPK (including ERK1/2, JNK1/2/3, and p38/MAPKs) and PI3K/Akt pathways [32]. The p90RSK is a group of serine/threonine kinase that plays a central role in the MAPK signaling cascade and is the direct downstream effector of ERK1/2. In addition, it is well known that ERK1/2 activation directly phosphorylates and activates p90RSK [33]. Therefore, it is logical to think that TGF- $\beta$-induced activation of p90RSK could be possibly mediated by ERK1/2. Since our major interest is to determine how p90RSK regulates TGF- $\beta$-induced EMT process, we did not focus on the activation mechanism of TGF- $\beta$-induced p90RSK, therefore it has to be further clarified. In this study, we for the first time, as far as we know, report an important role of p90RSK on pulmonary fibrosis by regulating Smad3 transcriptional activity.

In quiescent cells, p90RSK and CBP are associated in a complex, which inhibits p90RSK kinase activity and CBP acetyltransferase activity. This complex dissociates when p90RSK is phosphorylated after activation of the MAPK signaling pathway and regulates the activation of histone acetyltransferase (HAT) and the acetylations of specific substrates that lead to the coordinated modulation of gene expression [34]. Acetylation of Smad3 by acetyltransferase $\mathrm{CBP} / \mathrm{p} 300$ plays a critical role in the transcriptional regulatory function of Smad3. However, it remains to be determined whether p90RSK inhibition blocks TGF- $\beta 1$-Smad3 acetylation. Recently, Jo et al. showed that kaempferol (a nonselective inhibitor of p90RSK) inhibits TGF- $\beta 1$-induced EMT, migration, and MMP- 2 activation by inhibiting the phosphorylation of Smad3 at Thr 179 in its linker region in A549 cells [35]. In line with these observations, additional studies are needed to determine whether p90RSK activation is required for the TGF- $\beta 1$-mediated phosphorylation of the Smad3 linker region. 


\section{Cellular Physiology Cell Physiol Biochem 2020;54:195-210 \\ \begin{tabular}{l|l|l}
\hline DOI: 10.33594/000000214 & (c) 2020 The Author(s). Published by
\end{tabular} \\ and Biochemistry Published online: 22 February 2020 Cell Physiol Biochem Press GmbH\&Co. KG \\ Kim et al.: p90RSK Inhibition Ameliorates Pulmonary Fibrosis}

\section{Conclusion}

In the present study, p90RSK positively regulated TGF- $\beta 1$ signaling for Smad3 transcriptional activity, subsequent pro-fibrogenic responses, and EMT. Furthermore, in our mouse model of bleomycin-induced lung fibrosis, FMK suppressed the development of pulmonary fibrosis. These findings suggest targeting p90RSK might constitute a strategy for preventing the progression of pulmonary fibrosis.

\section{Acknowledgements}

This research was supported by the Medical Research Center Program (\#2015R1A5A2009124) and by the Basic Science Research Program (\#2018R1A2B6004664) of the Korean National Research Foundation (NRF) funded by the Ministry of Science, ICT, and Future Planning, and by the Basic Science Research Program through the NRF funded by the Ministry of Education (\#2019R1I1A1A01060129).

\section{Author Contributions}

Suji Kim, Jae Hyang Lim, Chang-Hoon Woo designed the study; Suji Kim, Jung-Hwa Han, Sujin Kim, Hee Jung Lee performed the experiments; Suji Kim wrote the original manuscript; Jae Hyang Lim, Jae-Ryong Kim and Chang-Hoon Woo reviewed and edited the manuscript.

\section{Disclosure Statement}

The authors have no conflict of interests to declare.

\section{References}

1 Noble PW, Barkauskas CE, Jiang D: Pulmonary fibrosis: patterns and perpetrators. J Clin Invest 2012;122:2756-2762.

2 Selman M, King TE, Pardo A: Idiopathic pulmonary fibrosis: prevailing and evolving hypotheses about its pathogenesis and implications for therapy. Ann Intern Med 2001;134:136-151.

3 Varga J, Abraham D: Systemic sclerosis: a prototypic multisystem fibrotic disorder. J Clin Invest 2007;117:557-567.

4 Ley B, Collard HR, King TE, Jr: Clinical course and prediction of survival in idiopathic pulmonary fibrosis. Am J Respir Crit Care Med 2011;183:431-440.

5 Noble PW, Albera C, Bradford WZ, Costabel U, Glassberg MK, Kardatzke D, King TE, Jr., Lancaster L, Sahn SA, Szwarcberg J, Valeyre D, du Bois RM: Pirfenidone in patients with idiopathic pulmonary fibrosis (CAPACITY): two randomised trials. Lancet 2011;377:1760-1769.

6 King TE, Jr., Bradford WZ, Castro-Bernardini S, Fagan EA, Glaspole I, Glassberg MK, Gorina E, Hopkins PM, Kardatzke D, Lancaster L, Lederer DJ, Nathan SD, Pereira CA, Sahn SA, Sussman R, Swigris JJ, Noble PW: A phase 3 trial of pirfenidone in patients with idiopathic pulmonary fibrosis. N Engl J Med 2014;370:20832092.

7 Meyer KC, Decker CA: Role of pirfenidone in the management of pulmonary fibrosis. Ther Clin Risk Manag 2017;13:427-437.

8 Wollin L, Wex E, Pautsch A, Schnapp G, Hostettler KE, Stowasser S, Kolb M: Mode of action of nintedanib in the treatment of idiopathic pulmonary fibrosis. Eur Respir J 2015;45:1434-1445.

9 Hostettler KE, Zhong J, Papakonstantinou E, Karakiulakis G, Tamm M, Seidel P, Sun Q Mandal J, Lardinois D, Lambers C, Roth M: Anti-fibrotic effects of nintedanib in lung fibroblasts derived from patients with idiopathic pulmonary fibrosis. Respir Res 2014;15:157. 


\section{Cellular Physiology Cell Physiol Biochem 2020;54:195-210 \begin{tabular}{ll|l|l|l}
\hline DOl: 10.33594/000000214 & ( 2020 The Author(s). Published by \\
\hline
\end{tabular} and Biochemistry Published online: 22 February 2020 Cell Physiol Biochem Press GmbH\&Co. KG \\ Kim et al.: p90RSK Inhibition Ameliorates Pulmonary Fibrosis}

10 Richeldi L, Cottin V, Flaherty KR, Kolb M, Inoue Y, Raghu G, Taniguchi H, Hansell DM, Nicholson AG, Le Maulf F, Stowasser S, Collard HR: Design of the INPULSIS trials: two phase 3 trials of nintedanib in patients with idiopathic pulmonary fibrosis. Respir Med 2014;108:1023-1030.

11 Hajari Case A, Johnson P: Clinical use of nintedanib in patients with idiopathic pulmonary fibrosis. BMJ Open Respir Res 2017;4:e000192.

12 Agostini C, Gurrieri C: Chemokine/cytokine cocktail in idiopathic pulmonary fibrosis. Proc Am Thorac Soc 2006;3:357-363.

13 Wynn TA: Cellular and molecular mechanisms of fibrosis. J Pathol 2008;214:199-210.

14 Morales-Ibanez O, Affo S, Rodrigo-Torres D, Blaya D, Millan C, Coll M, Perea L, Odena G, Knorpp T, Templin MF, Moreno M, Altamirano J, Miquel R, Arroyo V, Gines P, Caballeria J, Sancho-Bru P, Bataller R: Kinase analysis in alcoholic hepatitis identifies p90RSK as a potential mediator of liver fibrogenesis. Gut 2016;65:840-851.

15 Ballester B, Milara J, Cortijo J: Idiopathic Pulmonary Fibrosis and Lung Cancer: Mechanisms and Molecular Targets. Int J Mol Sci 2019;20:pii:E593.

16 Clement DL, Mally S, Stock C, Lethan M, Satir P, Schwab A, Pedersen SF, Christensen ST: PDGFRalpha signaling in the primary cilium regulates NHE1-dependent fibroblast migration via coordinated differential activity of MEK1/2-ERK1/2-p90RSK and AKT signaling pathways. J Cell Sci 2013;126:953-965.

17 Delehedde M, Seve M, Sergeant N, Wartelle I, Lyon M, Rudland PS, Fernig DG: Fibroblast growth factor-2 stimulation of $\mathrm{p} 42 / 44 \mathrm{MAPK}$ phosphorylation and IkappaB degradation is regulated by heparan sulfate/ heparin in rat mammary fibroblasts. J Biol Chem 2000;275:33905-33910.

18 Seko Y, Takahashi N, Tobe K, Ueki K, Kadowaki T, Yazaki Y: Vascular endothelial growth factor (VEGF) activates Raf-1, mitogen-activated protein (MAP) kinases, and S6 kinase (p90rsk) in cultured rat cardiac myocytes. J Cell Physiol 1998;175:239-246.

19 Frodin M, Gammeltoft S: Role and regulation of $90 \mathrm{kDa}$ ribosomal S6 kinase (RSK) in signal transduction. Mol Cell Endocrinol 1999;151:65-77.

20 Cohen MS, Zhang C, Shokat KM, Taunton J: Structural bioinformatics-based design of selective, irreversible kinase inhibitors. Science 2005;308:1318-1321.

21 Cuello F, Snabaitis AK, Cohen MS, Taunton J, Avkiran M: Evidence for direct regulation of myocardial Na+/ $\mathrm{H}+$ exchanger isoform 1 phosphorylation and activity by 90-kDa ribosomal S6 kinase (RSK): effects of the novel and specific RSK inhibitor fmk on responses to alpha1-adrenergic stimulation. Mol Pharmacol 2007;71:799-806.

22 Woo CH, Shishido T, McClain C, Lim JH, Li JD, Yang J, Yan C, Abe J: Extracellular signal-regulated kinase 5 SUMOylation antagonizes shear stress-induced antiinflammatory response and endothelial nitric oxide synthase expression in endothelial cells. Circ Res 2008;102:538-545.

23 Itoh S, Ding B, Bains CP, Wang N, Takeishi Y, Jalili T, King GL, Walsh RA, Yan C, Abe J: Role of p90 ribosomal S6 kinase (p90RSK) in reactive oxygen species and protein kinase $\mathrm{C}$ beta (PKC-beta)-mediated cardiac troponin I phosphorylation. J Biol Chem 2005;280:24135-24142.

24 Nigro P, Abe J, Woo CH, Satoh K, McClain C, O’Dell MR, Lee H, Lim JH, Li JD, Heo KS, Fujiwara K, Berk BC: PKCzeta decreases eNOS protein stability via inhibitory phosphorylation of ERK5. Blood 2010;116:19711979.

25 Kasai H, Allen JT, Mason RM, Kamimura T, Zhang Z: TGF-beta1 induces human alveolar epithelial to mesenchymal cell transition (EMT). Respir Res 2005;6:56.

26 Voulgari A, Pintzas A: Epithelial-mesenchymal transition in cancer metastasis: mechanisms, markers and strategies to overcome drug resistance in the clinic. Biochim Biophys Acta 2009;1796:75-90.

27 Aschner Y, Downey GP: Transforming Growth Factor-beta: Master Regulator of the Respiratory System in Health and Disease. Am J Respir Cell Mol Biol 2016;54:647-655.

28 He W, Tan R, Dai C, Li Y, Wang D, Hao S, Kahn M, Liu Y: Plasminogen activator inhibitor-1 is a transcriptional target of the canonical pathway of Wnt/beta-catenin signaling. J Biol Chem 2010;285:24665-24675.

29 Heo KS, Le NT, Cushman HJ, Giancursio CJ, Chang E, Woo CH, Sullivan MA, Taunton J, Yeh ET, Fujiwara K, Abe J: Disturbed flow-activated p90RSK kinase accelerates atherosclerosis by inhibiting SENP2 function. J Clin Invest 2015;125:1299-1310.

30 Buck M, Chojkier M: A ribosomal S-6 kinase-mediated signal to C/EBP-beta is critical for the development of liver fibrosis. PLoS One 2007;2:e1372. 
31 Buck M, Chojkier M: C/EBPbeta-Thr217 phosphorylation signaling contributes to the development of lung injury and fibrosis in mice. PLoS One 2011;6:e25497.

32 Zhang YE: Non-Smad pathways in TGF-beta signaling. Cell Res 2009;19:128-139.

33 Romeo Y, Zhang X, Roux PP: Regulation and function of the RSK family of protein kinases. Biochem J 2012;441:553-569.

34 Merienne K, Pannetier S, Harel-Bellan A, Sassone-Corsi P: Mitogen-regulated RSK2-CBP interaction controls their kinase and acetylase activities. Mol Cell Biol 2001;21:7089-7096.

35 Jo E, Park SJ, Choi YS, Jeon WK, Kim BC: Kaempferol Suppresses Transforming Growth Factor-beta1Induced Epithelial-to-Mesenchymal Transition and Migration of A549 Lung Cancer Cells by Inhibiting Akt1-Mediated Phosphorylation of Smad3 at Threonine-179. Neoplasia (New York, NY) 2015;17:525-537. 